\title{
Electrophilic behavior of 3-methyl-2-methylthio-1,3,4-thiadiazolium salts: a multimodal theoretical approach
}

\author{
Arturo Espinosa,* a Antonio Frontera, ${ }^{\text {b }}$ Rafaela García, ${ }^{a}$ Miguel A. Soler , \\ and Alberto Tárraga * a \\ a Departamento de Química Orgánica, Facultad de Química, Campus de Espinardo, \\ Universidad de Murcia, E-30071 Murcia, Spain \\ ${ }^{b}$ Departament de Química, Universitat de les Illes Balears, E-07071 Palma de Mallorca, Spain \\ E-mail: artuesp@um.es
}

\section{Dedicated to Professors Pedro Molina and José Elguero on the occasion of their respective $60^{\text {th }}$ and $70^{\text {th }}$ birthdays}

(received 30 Dec 04; accepted 21 Jun 05; published on the web 28 Jun 05)

\begin{abstract}
The chemical reactivity of 3-methyl-2-methylthio-1,3,4-thiadiazolium salts towards a variety of nucleophiles has been examined from several theoretical points of view including thermochemical analysis of the global reactions, the evaluation of aromaticity-related parameters - ASE (Aromatic Stabilization Energy), NICS (Nucleus Independent Chemical Shift), HOMA (Harmonic Oscillator Model of Aromaticity) - for the resulting products, the qualitative application of the HSAB- (Hard- and Soft- Acid and Bases) principle, quantitative calculation of DFT- (Density Functional Theory)- derived local and group properties such as softness and philicity, as well as the estimation of interaction energies. Two well-distinguished reaction paths are characterized depending on the nucleophilicity of the reagent.
\end{abstract}

Keywords: 1,3,4-Thiadiazolium salts, 2-amino-1,3,4-thiadiazolines, frontier molecular orbitals, MIPp (Molecular Interaction Potential with polarization), softness, philicity, interaction energies, aromaticity, ASE, NICS, HOMA

\section{Introduction}

2-Amino-1,3,4-thiadiazole systems have received much attention owing to their industrial applications, ${ }^{1}$ as well as their wide range of biological activities, ${ }^{2}$ and their incorporation into supramolecular entities. ${ }^{3}$ To the best of our knowledge two main routes have been developed for access to these amino- functionalized heterocycles: one starts from open-chain thiosemicarbazide precursors, ${ }^{4}$ and the other more common methods use nucleophilic displacements on a suitably 
functionalized preformed thiadiazole ring. ${ }^{5}$ In the last category, we have recently reported a versatile strategy for the synthesis of highly functionalized 2-oxo-, 2-thioxo-, 2-imino-, or 2methylene-1,3,4-thiadiazolines with a C-, N-, or S-substituent at the position- 5 (2), as well as the respective cationic or mesoionic counterparts, by reaction of the appropriate $\mathrm{O}-, \mathrm{N}-$ or $\mathrm{C}$ nucleophiles with the corresponding 5-substituted 3-methyl-2-methylthio-1,3,4-thiadiazolium salts 1 (Figure 1). ${ }^{6}$ 2-Thioxo-thiadiazolines were only obtained as S-demethylation products when halide or carboxylate anions were present in the reaction mixture. This different behavior towards the latter nucleophiles prompted us to explore both the stability of the final products resulting from every possible reaction path - in order to detect any possible thermodynamic control - and the exact nature of the donor-acceptor interactions taking place in every case.
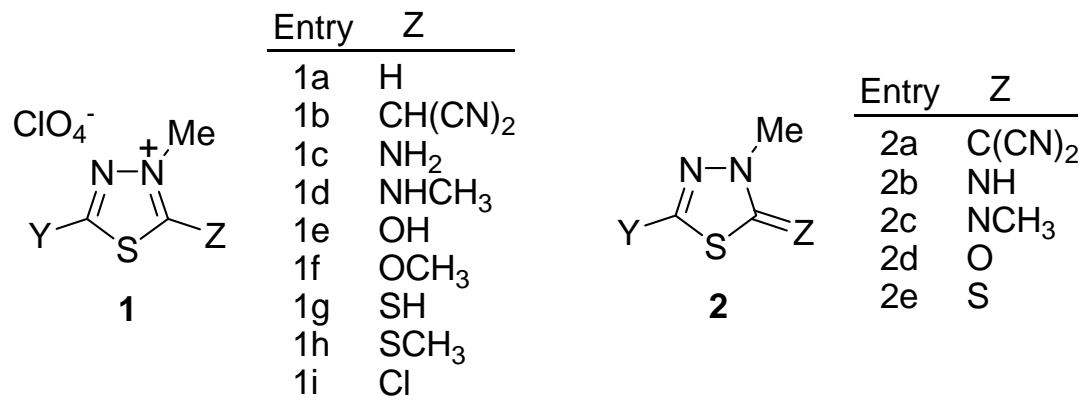

Figure 1

The evaluation of the stability of all possible reaction products arising from the treatment of 2-methylthiothiadiazolium salts (1) with nucleophiles might afford a valuable criterion to explain the major species obtained in every case, for the limiting situation in which the experiments were carried out under conditions of thermodynamic control. This evaluation can be made by estimating the corresponding reaction- (or formation-) energies, or by invoking qualitative energy-based concepts such as aromaticity when planar cyclic fully conjugated $\pi$-electron systems are involved. Although the term, "aromaticity" is universally used, it is not a directly measurable quantity. However, it is well accepted that this phenomenon can be characterized mainly by three descriptors related to aromatic features: ${ }^{7}$ (i) the ASE calculated on the basis of homodesmotic reactions, ${ }^{8}$ as an expression of the higher stability of these systems when compared with their acyclic or cyclic olefinic or conjugated unsaturated analogues; (ii) the HOMA, ${ }^{9}$ considered the most reliable geometrical index, that accounts for the bond-length tendency to be halfway between those of single and double bonds; and (iii) the NICS ${ }^{10}$ as a criterion for evaluating the diatropic $\pi$ - ring-current induced by an external magnetic field.

For analyzing the electrophile-nucleophile interactions, the MIPp method ${ }^{11}$ has been shown to be a valuable tool for predicting molecular reactivity and for rationalizing molecular interactions such as hydrogen bonds and cation- $\pi$ interactions. ${ }^{12}$ MIPp is an improved generalization of the molecular electrostatic potential (MEP) ${ }^{13}$ in which three terms contribute to the interaction energy: (i) an electrostatic term identical to the MEP, (ii) a classical dispersionrepulsion term, ${ }^{14}$ and (iii) a polarization term derived from perturbational theory. ${ }^{15}$ 
On the other hand, an obvious qualitative explanation for the interaction between reagents comes from Pearson's HSAB principle ${ }^{16}$ and application of the statement, "hard likes hard and soft likes soft" at the local level. Later, the concept of softness ${ }^{17}$ has been found to be intimately related to fundamental variables of DFT, ${ }^{18}$ thus providing a more solid theoretical basis to the HSAB principle, ${ }^{19}$ and allowing one to quantify the hardness or the softness of a chemical species by using operational formulas. ${ }^{20}$ Various applications of both global and local reactivity descriptors within this context of chemical reactivity and site selectivity have been reviewed in detail. ${ }^{21}$

In particular, the electronic chemical potential, ${ }^{22} \mu$, is the derivative of the energy of the molecule (or atom) with respect to its number of electrons $(\mathrm{N})$ at constant external potential $\mathrm{v}(\mathbf{r})$ (i.e., identical nuclear charges and positions), and it is identified as the opposite of the electronegativity, $\chi$ (Eq. 1). Similarly, the global hardness, ${ }^{19} \eta$, is the related second derivative, or the change of the chemical potential with respect to the number of electrons at constant external potential, and is inversely related to the global softness, $S$ (Eq. 2).

$$
\begin{aligned}
& \mu=-\chi=\left(\frac{\partial \mathrm{E}}{\partial \mathrm{N}}\right)_{\mathrm{v}} \\
& 2 \eta=\frac{1}{S}=\left(\frac{\partial^{2} \mathrm{E}}{\partial^{2} \mathrm{~N}}\right)_{\mathrm{v}}=\left(\frac{\partial \mu}{\partial \mathrm{N}}\right)_{\mathrm{v}}
\end{aligned}
$$

In a finite difference approximation to the derivatives, these quantities can be obtained from the vertical ionization potential $(I)$ and the electron affinity $(A)$ corresponding to the energy change upon discrete variation of the number of electrons to $\mathrm{N}-1$ and $\mathrm{N}+1$, respectively (Eq. 34)

$$
\begin{aligned}
& \mu=-\frac{1}{2(I+A)} \\
& S=\frac{1}{I-A}
\end{aligned}
$$

The above DFT-based properties can be obtained at the local level by means of the Fukui function $f(\mathbf{r}) .^{23}$ In a finite-differences approximation, the condensed Fukui functions for ionic reactions, $f_{k}^{\alpha}$ (with $\alpha=+,-$ ) are obtained first by condensing the electronic density to the charge of each atom, $k$, in the molecule, and afterwards differentiating with respect to the total number of electrons (Eqs. 5,6): $:^{24}$

$$
\begin{array}{ll}
f_{k}^{+}=q_{k, \mathrm{~N}+1}-q_{k, \mathrm{~N}} & \text { for nucleophilic attack } \\
f_{k}^{-}=q_{k, \mathrm{~N}}-q_{k, \mathrm{~N}-1} & \text { for electrophilic attack }
\end{array}
$$


where $q_{k, \mathrm{~N}}, q_{k, \mathrm{~N}+1}$ and $q_{k, \mathrm{~N}-1}$ are the charges of the $k$ th atom in the molecule with $\mathrm{N}, \mathrm{N}+1$ and $\mathrm{N}-1$ electrons, respectively, all with the ground state geometry of the $\mathrm{N}$ - electron system, in order to fulfill the condition of constant external potential.

Closely related to the Fukui function and its condensed versions is the condensed local softness ${ }^{25}$ for nucleophilic $\left(s_{k}^{+}\right)$or electrophilic $\left(s_{k}{ }^{-}\right)$attack, obtained from the global softness and the corresponding condensed Fukui functions (Eq. 7).

$$
s_{k}^{\alpha}=S \cdot f_{k}^{\alpha} \quad(\text { with } \alpha=+,-)
$$

As stated by the HSAB principle, the interacting sites of a nucleophile--electrophile pair will have local softnesses as close as possible, and can be rationalized from a local-global viewpoint ${ }^{26}$ in the sense that a molecule, $A$, containing several possible interaction sites, $a_{j}(j=1$, $2, \ldots)$, will interact preferentially with another molecule, $\mathrm{B}$, yielding the smallest of the possible $\Delta_{j}^{s}$ values (Eq. 8).

$$
\Delta_{j}^{s}=\left(s_{\mathrm{Aj}}-S_{\mathrm{B}}\right)^{2}
$$

A more detailed analysis of such a situation may be made in terms of the interaction energy by making the assumption that it may be divided into two steps which can be taken as happening successively ${ }^{27}$ (Eq. 9). The first terminus, $\Delta \mathrm{E}_{\mathrm{v}}$, results from the chemical-potential equalization principle and corresponds to the charge-transfer process between $\mathrm{A}$ and $\mathrm{B}$ at constant external potential, whereas the second, $\Delta \mathrm{E}_{\mu}$, is equivalent to a reshuffling of the charge distribution at constant chemical potential and is usually a manifestation of the so-called maximum hardness principle, ${ }^{28}$ stating that, "molecules try to arrange themselves to be as hard as possible".

$$
\Delta \mathrm{E}_{\text {int }}=\Delta \mathrm{E}_{\mathrm{v}}+\Delta \mathrm{E}_{\mu}
$$

From the local viewpoint:

$$
\left(\Delta \mathrm{E}_{\mathrm{int}}\right)_{\mathrm{A}}^{k} \cong-\frac{1}{2} \frac{\left(\mu_{\mathrm{A}}-\mu_{\mathrm{B}}\right)^{2}}{s_{\mathrm{A} k}+S_{\mathrm{B}}} s_{\mathrm{A} k} \cdot S_{\mathrm{B}}-\frac{1}{2} \frac{\lambda}{s_{\mathrm{A} k}+S_{\mathrm{B}}}
$$

where the (positive) factor $\lambda$ has been shown to be proportional to an effective number of valence electrons taking part in the reaction between $\mathrm{A}$ and $\mathrm{B},{ }^{19 \mathrm{~b},}{ }^{27 \mathrm{~b}}$ also bearing information on the system $\mathrm{AB}$ both at and out of equilibrium (when $\mathrm{A}$ and $\mathrm{B}$ are far apart). This equation can be studied as a function of $\lambda$ and written as below, where $\Delta \mathrm{E}_{\mu}^{\prime}=\Delta \mathrm{E}_{\mu}$ for $\lambda=1$.

$$
\left(\Delta \mathrm{E}_{\text {int }}\right)_{\mathrm{A}}^{k} \cong \Delta \mathrm{E}_{\mathrm{v}}+\lambda \cdot \Delta \mathrm{E}_{\mu}^{\prime}
$$

The electrophilicity parameter, $\omega$, (Eq. 12) was introduced by Parr et $a .^{29}$ as a global reactivity index measuring the stabilization in energy when the system acquires an additional electronic charge, $\Delta \mathrm{N}$, from the environment;

$$
\omega=\frac{\mu^{2}}{2 \eta}=\mu^{2} \cdot S
$$

Recently, the generalized concept of philicity at the local and condensed levels (Eq. 13) has been proposed by Chattaraj et al., ${ }^{30}$ containing almost all the information about hitherto known different global- and local- reactivity and selectivity descriptors, in addition to the information regarding the electrophilic and nucleophilic power of a given atomic site in a molecule. 


$$
\omega_{k}^{\alpha}=\omega \cdot f_{k}^{\alpha} \quad(\text { with } \alpha=+,-)
$$

For situations in which condensed local softness could not provide the correct intermolecular reactivity trends, the group softness-, ${ }^{31} S_{\mathrm{g}}$ (Eq. 14) and group philicity-, ${ }^{32} \omega_{\mathrm{g}}$ (Eq. 15) descriptors have been highlighted, which are obtained by summing the condensed local property - softness or philicity - over all of the $n$ neighboring atoms attached to the reactive site $k$.

$$
\begin{aligned}
& S_{\mathrm{g}}=\sum_{j=1}^{n} s_{j} \\
& \omega_{\mathrm{g}}=\sum_{j=1}^{n} \omega_{j}
\end{aligned}
$$

\section{Results and Discussion}

The 3-methyl-2-methylthio-1,3,4-thiadiazolium salt $\mathbf{1 h},{ }^{\text {a }}$ which for the present study has been chosen unsubstituted at C-5 for the sake of simplicity, has three main electrophilic centers which could give rise to different products when treated with nucleophiles (Scheme 1). Thus, nucleophilic attack at the C-2 position of the ring would lead to the substitution products $\mathbf{1 b}-\mathbf{i}$, with methanethiol acting as leaving group, whereas attack at the S- or the N-3- methyl carbon atoms would yield the demethylation products, thiadiazolinethione $2 \mathbf{e}$ or 2-methylthiothiadiazole $3 \mathbf{b}$, respectively.

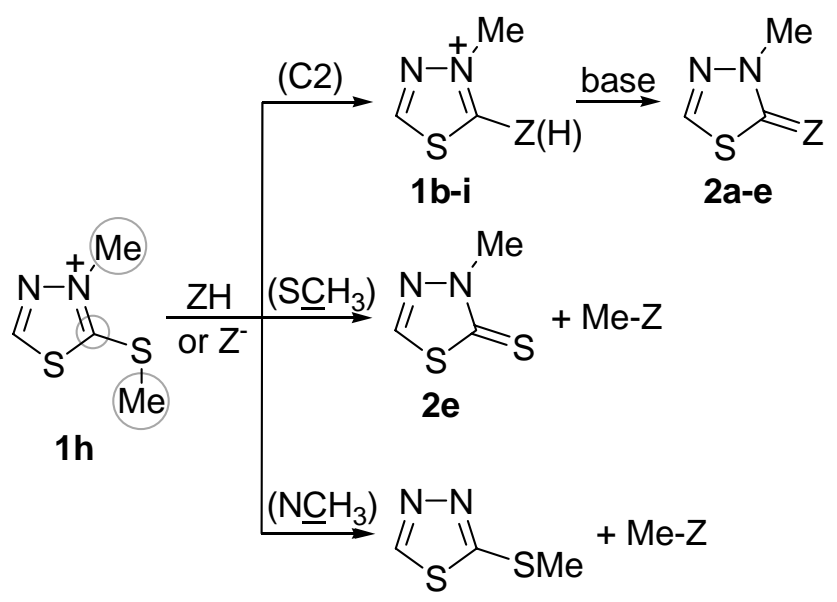

3b

\section{Scheme 1}

A straightforward type of analysis to rationalize the preferential formation of products resulting from each reaction path comes from a comparison of their stabilities. The Gibbs freeenergies for all possible paths in the reaction of $\mathbf{1 h}$ with typical nucleophiles as depicted in 
Scheme 1 have been calculated and the results collected in Table 1. In all cases, the reactants have been considered not as isolated species but as the more stable complex between $\mathbf{1 h}$ and the nucleophile. Similarly, the products have been computed as their more stable complex between the leaving-group, methanethiol or methanethiolate (path $\mathrm{C} 2$ ), or methylated nucleophile (paths $\mathrm{SCH}_{3}$ and $\mathrm{NCH}_{3}$ ) and the corresponding thiadiazole derivative. In all cases, solvent effects (ethanol) have been considered through single-point energy (SPE) calculations using the polarizable continuum model (PCM) on the gas-phase optimized geometries. Despite the fact that these reactions are usually carried out in the presence of triethylamine in order to obtain the deprotonation products whenever possible, and with the aim of comparison between paths, the initially formed thiadiazolium cations $\mathbf{1 b}-\mathbf{i}$ have been taken as the final products when the nucleophiles attack the $\mathrm{C}-2$ position, except when using the hydroxide or hydrogensulfide anions or the anion of malononitrile. In these cases $\mathbf{2 a}, \mathbf{2} \mathbf{d}$ or $\mathbf{2 e}$ were used as final products owing to the instability of the highly acidic $\mathbf{1 b}, \mathbf{1 e}$ and $\mathbf{1 f}$ in the required basic conditions. Indeed, from the optimization of the $\mathbf{1 b} \cdot \mathrm{MeS}^{-}$, $\mathbf{1 e} \cdot \mathrm{MeS}^{-}$and $\mathbf{1 f} \cdot \mathrm{MeS}^{-}$complexes, it has been observed that the methanethiolate leaving group is basic enough to abstract one proton from the dicyanomethyl, hydroxy or mercapto substituent, leading to the corresponding thiadiazoline-methanethiol complex. With $\mathrm{SH}_{2}$ or $\mathrm{SH}^{-}$as nucleophiles, the same products are obtained by attack at the C-2 or the $\mathrm{SCH}_{3}$ positions, as a consequence of the subsequent acid-base reaction between the product and the leaving group. From the data in Table 1 it is apparent that only O- nucleophiles excepting methoxide anion, yield the product of $\mathrm{C}-2$ attack as the most stable one, while chloride and anionic S-nucleophiles give the products originating through the $\mathrm{SCH}_{3}$ path as the most stable compounds, in agreement with experiments. These results point to thermodynamic control, insofar as the most stable product coincides with that obtained experimentally.

In contrast, the behavior exhibited by $\mathrm{C}$ - or $\mathrm{N}$ - nucleophiles cannot be rationalized by thermodynamic control, as the products resulting from the $\mathrm{C}-2$ paths are not the more stable ones, even when using a basic medium (taking $\mathrm{Me}_{3} \mathrm{~N}$ to model the basic behavior of the $\mathrm{Et}_{3} \mathrm{~N}$ used experimentally). However, it is worth noting that the removal of volatile methanethiol from the reaction medium could explain the preferential obtention of these products, 1c-d, despite its higher $\Delta \mathrm{G}^{\mathrm{o}}$ values, by simple displacement of the equilibrium to the right.

Positive $\Delta \mathrm{G}^{\mathrm{o}}$ values for the attack of neutral O- nucleophiles at C-2, although lower than for the $\mathrm{SCH}_{3}$ path, reflect the fact that the resulting products 1e-f have never been obtained experimentally under neutral conditions, thus explaining the fact that $\mathbf{1 h}$ remains stable in both dry or water-containing alcoholic solutions. The high acidity of 1e accounts for its observed tendency to undergo fast and quantitative deprotonation by addition of triethylamine, affording the thiadiazolone $\mathbf{2 d}$. 
Table 1. Calculated ${ }^{\mathrm{a}}$ Gibbs free energies $(\mathrm{kcal} / \mathrm{mol})$ in ethanol ${ }^{\mathrm{b}}$ for the reaction of $\mathbf{1 h}$ with typical nucleophiles following the three expected paths

\begin{tabular}{|c|c|c|c|c|c|c|c|}
\hline Nucleophile & & & & $\Delta \mathrm{G}^{\mathrm{o}}$ and product & & & Exper. $^{\mathrm{c}}$ \\
\hline & & $\mathrm{C}-2$ & & $-\mathrm{SCH}_{3}$ & & $-\mathrm{NCH}_{3}$ & \\
\hline$(\mathrm{NC})_{2} \mathrm{CH}^{-}$ & -21.4 & 2a $\cdot \mathrm{MeSH}$ & -33.2 & $\mathbf{2 e} \cdot \mathrm{MeCH}(\mathrm{CN})_{2}$ & -27.5 & $\mathbf{3 b} \cdot \mathrm{MeCH}(\mathrm{CN})_{2}$ & $\mathrm{C}-2$ \\
\hline $\mathrm{NH}_{3}$ & $\begin{array}{r}-7.6 \\
-10.4\end{array}$ & $\begin{array}{l}\text { 1c } \cdot \mathrm{MeSH} \\
\text { 2b } \cdot \mathrm{MeSH}^{\mathrm{d}}\end{array}$ & -12.7 & $\mathbf{2 e} \cdot \mathrm{MeNH}_{3}^{+}$ & -7.9 & 3b $\cdot \mathrm{MeNH}_{3}^{+}$ & $\mathrm{C}-2$ \\
\hline $\mathrm{CH}_{3} \mathrm{NH}_{2}$ & $\begin{array}{l}-12.5 \\
-18.2\end{array}$ & $\begin{array}{l}\text { 1d·MeSH } \\
\text { 2c } \cdot \mathrm{MeSH}^{\mathrm{d}}\end{array}$ & -20.8 & $\mathbf{2 e} \cdot \mathrm{Me}_{2} \mathrm{NH}_{2}{ }^{+}$ & -14.8 & $\mathbf{3 b} \cdot \mathrm{Me}_{2} \mathrm{NH}_{2}^{+}$ & $\mathrm{C}-2$ \\
\hline $\mathrm{H}_{2} \mathrm{O}$ & $\begin{array}{r}1.7 \\
-25.1\end{array}$ & $\begin{array}{l}\mathbf{1 e} \cdot \mathrm{MeSH} \\
\text { 2d·MeSH }\end{array}$ & $\begin{array}{r}10.9 \\
-10.2\end{array}$ & $\begin{array}{l}\mathbf{2 e} \cdot \mathrm{MeOH}_{2}^{+} \\
\mathbf{2 e} \cdot \mathrm{MeOH}^{\mathrm{d}}\end{array}$ & $\begin{array}{r}6.2 \\
-3.8\end{array}$ & $\begin{array}{l}\text { 3b } \cdot \mathrm{MeOH}_{2}^{+} \\
\text {3b } \cdot \mathrm{MeOH}^{\mathrm{d}}\end{array}$ & $\begin{array}{l}\text { None } \\
\text { C-2 }\end{array}$ \\
\hline $\mathrm{OH}^{-}$ & -49.7 & 2d·MeSH & -34.7 & $\mathbf{2 e} \cdot \mathrm{MeOH}$ & -28.4 & 3b·MeOH & $\mathrm{C}-2$ \\
\hline $\mathrm{CH}_{3} \mathrm{OH}$ & 6.5 & $\mathbf{1 f} \cdot \mathrm{MeSH}$ & 8.3 & $\mathbf{2 e} \cdot \mathrm{Me}_{2} \mathrm{OH}^{+}$ & 4.4 & $3 \mathbf{b} \cdot \mathrm{Me}_{2} \mathrm{OH}^{+}$ & None \\
\hline $\mathrm{CH}_{3} \mathrm{O}^{-}$ & -13.5 & 1f $\cdot \mathrm{MeS}^{-}$ & -31.2 & $\mathbf{2 e} \cdot \mathrm{Me}_{2} \mathrm{O}$ & -26.7 & $\mathbf{3 b} \cdot \mathrm{Me}_{2} \mathrm{O}$ & e \\
\hline $\mathrm{H}_{2} \mathrm{~S}$ & 1.8 & 1g.MeSH & 1.8 & 1g.MeSH & -2.0 & 3b $\cdot \mathrm{MeSH}_{2}^{+}$ & - \\
\hline $\mathrm{HS}^{-}$ & -29.3 & $\mathbf{2 e} \cdot \mathrm{MeSH}$ & -29.3 & 2e·MeSH & -22.2 & 3b·MeSH & - \\
\hline $\mathrm{CH}_{3} \mathrm{SH}$ & 0.0 & $\mathbf{1 h} \cdot \mathrm{MeSH}$ & 2.2 & $\mathbf{2 e} \cdot \mathrm{Me}_{2} \mathrm{SH}^{+}$ & -3.1 & 3b $\cdot \mathrm{Me}_{2} \mathrm{SH}^{+}$ & - \\
\hline $\mathrm{CH}_{3} \mathrm{~S}^{-}$ & 0.0 & $\mathbf{1 h} \cdot \mathrm{MeS}^{-}$ & -35.7 & $\mathbf{2 e} \cdot \mathrm{Me}_{2} \mathrm{~S}$ & -30.3 & $\mathbf{3 b} \cdot \mathrm{Me}_{2} \mathrm{~S}$ & $-\mathrm{SCH}_{3}{ }^{\mathrm{f}}$ \\
\hline $\mathrm{Cl}^{-}$ & 40.2 & $\mathbf{1 i} \cdot \mathrm{MeS}^{-}$ & -10.1 & $2 \mathbf{e} \cdot \mathrm{MeCl}$ & -0.5 & $3 \mathbf{b} \cdot \mathrm{MeCl}$ & $-\mathrm{SCH}_{3}$ \\
\hline
\end{tabular}

${ }^{a}$ At B3LYP/6-31+G* level. ${ }^{\mathrm{b}}$ Using the PCM model. ${ }^{\mathrm{c}}$ See ref. $6 .{ }^{\mathrm{d}}$ Corrected by means of the $\mathrm{Me}_{3} \mathrm{~N} \rightarrow \mathrm{Me}_{3} \mathrm{NH}^{+}$half-reaction. ${ }^{\mathrm{e}}$ Not reported for methoxide ions, but carboxylate salts are reported to give attack at $-\mathrm{SCH}_{3} .{ }^{\mathrm{f}}$ Unpublished results.

The higher thermodynamic stability and preferential formation, in some cases, of thiadiazolines 2a-e as more stable products compared to the Hückel-type thiadiazolium cations, $\mathbf{1 b}-\mathbf{i}$ or the neutral thiadiazole, $\mathbf{3 b}$, can at first sight be seen as a matter of some controversy. The nucleophilic substitution at the N-methyl C-atom of $\mathbf{1 h}$ yields 2-methylthio-1,3,4-thiadiazole, 3b, a simple derivative of the parent unsubstituted 1,3,4-thiadiazole 3a, whose aromaticity is beyond all doubt and has been studied recently elsewhere. ${ }^{7}$ Similarly, the nucleophilic substitution at $\mathrm{C} 2$ gives a 2-substituted-2-methyl-1,3,4-thiadiazolium cation, 1b-i, also exhibiting the structural requirements for aromatic compounds. In the cases where the thiadiazolium salts still bear an acidic proton on the incoming atom linked to $\mathrm{C}-2$, they usually undergo deprotonation in the basic medium, affording 3-methyl-2-methylene-, 2-imino-, 2-oxo-, or 2-thioxo-1,3,4-thiadiazolines, 2a-e, which are not, in principle, fully conjugated cyclic $\pi$ systems, and are therefore expected to have low, if any, aromaticity. The third reaction path, the substitution reaction at the S-methyl carbon atom, yields the above-mentioned 3-methyl-2thioxo-1,3,4-thiadiazoline, $2 \mathbf{e}$.

The ASE is often considered as the principal criterion of aromaticity since it governs the reactions and much of the chemical behavior. For a correct definition we have applied an 
homodesmotic reaction scheme (Scheme 2) similar to that recently reported by Cyrañski et al. ${ }^{7}$ This scheme allows cancellation of strain effects, since all reference compounds are fivemembered rings computed in their most stable conformations, and additional effects like topological charge stabilization and/or heteroatom-heteroatom interactions should be diminished when compared with other homodesmotic/isodesmotic reaction schemes. ${ }^{33}$

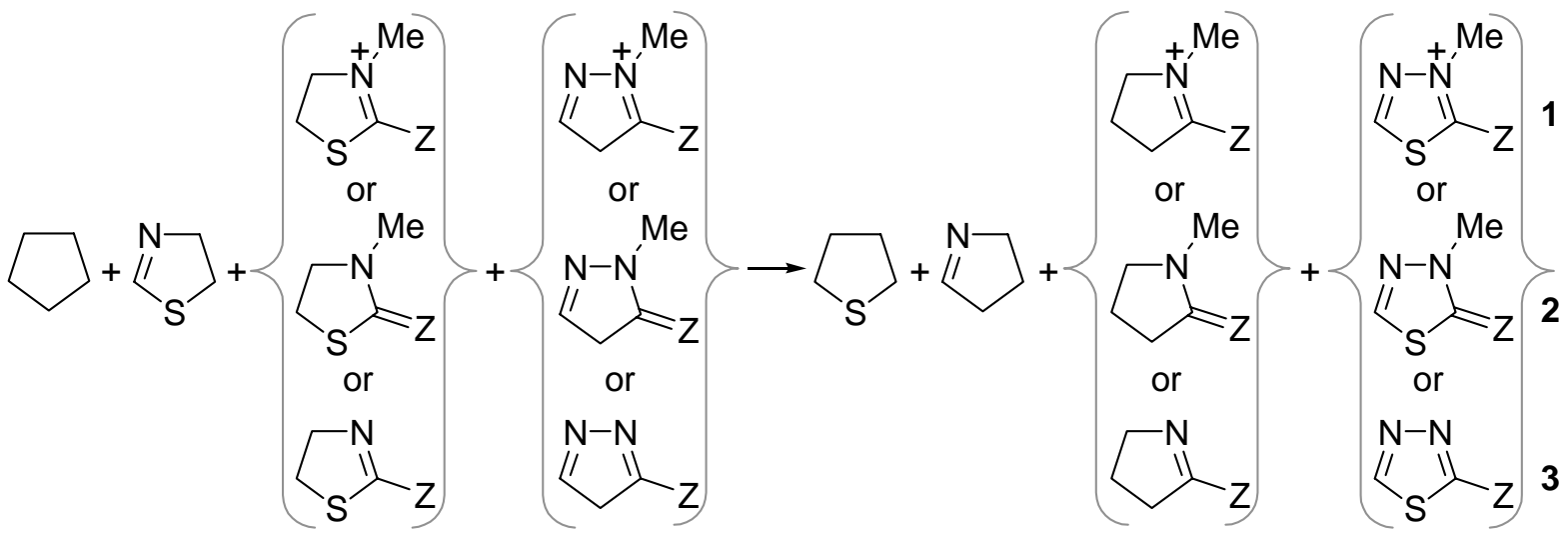

Scheme 2. Homodesmotic reactions used for the calculation of ASE values.

Compounds 1a and 3a (both with Z: H) have also been included in the present study for the sake of comparison, and the results obtained are summarized in Table 2.

As has already been mentioned, a second important criterion related to the structural aspects of aromatic compounds makes use of Krygowski's HOMA geometry-based descriptor, defined ${ }^{9 b}$ by eq. 16 . In this, $\mathrm{N}$ is the number of bonds taken into the summation, $\alpha$ is an empirical constant

$$
\mathrm{HOMA}=1-\frac{\alpha}{\mathrm{N}} \sum_{i=1}^{\mathrm{N}}\left(R_{o p t}-R_{i}\right)^{2}
$$

$\left(257.7 \AA^{-2}\right)$ fixed so that HOMA vanishes for a model non-aromatic system, and HOMA $=1$ for a system with all bond lengths equal to an optimal value $R_{\text {opt }}(1.388 \AA$ ), assumed to be realized for fully aromatic systems, and $R_{i}$ standing for every running bond length. To account for carbon- heteroatom and heteroatom-heteroatom bonds, a modification ${ }^{9 c}$ is made on the basis of Pauling numbers ${ }^{34}$ and thereafter using, "virtual carbon-carbon bonds," $r_{i}$ in eq. 18. Making use of the (virtual) average bond length for the ring system, $r_{a v}$, the deviation from the aromatic $\mathrm{HOMA}=1$ value is often separated into two terms (Eq. 17) describing different contributions to a decrease in aromaticity: EN due to bond-elongation (Eq. 18), and GEO due to bond-length alternation (Eq. 19). When $r_{a v}$ is shorter than $R_{o p t}$ the term EN must be taken as a negative contribution, accounting for the fact that the shorter is the bond, the greater is its energy; ${ }^{35}$ it is written here in a more compact form than in Krygowski's original paper. ${ }^{9 b}$ 
Table 2. Calculated ASE (in kcal/mol), HOMA, NICS (in ppm), CHELPG charges (in a.u.) and Wiberg bond indices for compounds 1-3

\begin{tabular}{|c|c|c|c|c|c|c|c|c|c|c|}
\hline & \multicolumn{4}{|c|}{$\mathrm{ASE}^{\mathrm{a}}$} & \multicolumn{2}{|c|}{$\mathrm{NICS}^{\mathrm{d}}$} & \multicolumn{3}{|c|}{ Charge $^{\mathrm{e}}$} & \multirow{2}{*}{$\frac{\mathrm{WBI}^{\mathrm{e}}}{\mathrm{C} 2-\mathrm{Z}}$} \\
\hline Entry & Z & & $\begin{array}{c}\text { Solv. } \\
\text { B }\end{array}$ & $\mathrm{HOMA}^{\mathrm{c}}$ & 0 & 1 & $\mathrm{~S} 1$ & N3 & Z & \\
\hline $1 \mathrm{a}$ & $\mathrm{H}$ & 8.74 & 10.44 & 0.800 & -13.32 & -11.09 & 0.287 & 0.347 & 0.238 & 0.901 \\
\hline $\mathrm{b}$ & $\mathrm{CH}(\mathrm{CN})_{2}$ & 8.02 & 10.04 & 0.802 & -11.99 & -10.55 & 0.271 & 0.432 & 0.245 & 0.987 \\
\hline $\mathrm{c}$ & $\mathrm{NH}_{2}$ & 5.96 & 7.17 & 0.643 & -10.51 & -7.75 & 0.165 & 0.256 & 0.129 & 1.309 \\
\hline d & $\mathrm{NHCH}_{3}$ & 5.59 & 7.06 & 0.634 & -10.67 & -7.88 & 0.155 & 0.271 & 0.285 & 1.317 \\
\hline e & $\mathrm{OH}$ & 6.76 & 8.97 & 0.686 & -11.25 & -8.58 & 0.172 & 0.349 & 0.057 & 1.149 \\
\hline $\mathrm{f}$ & $\mathrm{OCH}_{3}$ & 6.59 & 8.52 & 0.675 & -11.36 & -8.67 & 0.145 & 0.297 & 0.146 & 1.168 \\
\hline $\mathrm{g}$ & $\mathrm{SH}$ & 7.30 & 9.39 & 0.725 & -11.65 & -9.50 & 0.216 & 0.465 & 0.293 & 1.217 \\
\hline $\mathrm{h}$ & $\mathrm{SCH}_{3}$ & 6.99 & 8.37 & 0.714 & -11.55 & -9.49 & 0.193 & 0.346 & 0.296 & 1.237 \\
\hline $\mathrm{i}$ & $\mathrm{Cl}$ & 7.80 & 9.13 & 0.771 & -12.04 & -9.95 & 0.279 & 0.405 & 0.182 & 1.208 \\
\hline $2 a$ & $\mathrm{C}(\mathrm{CN})_{2}$ & 5.08 & 6.33 & 0.592 & -9.15 & -6.57 & 0.049 & 0.267 & -0.436 & 1.376 \\
\hline $\mathrm{b}$ & $\mathrm{NH}$ & 4.68 & 5.34 & 0.362 & -7.50 & -4.80 & -0.120 & 0.282 & -0.400 & 1.752 \\
\hline $\mathrm{c}$ & $\mathrm{NCH}_{3}$ & 4.17 & 4.27 & 0.327 & -8.18 & -5.34 & -0.120 & 0.231 & -0.320 & 1.717 \\
\hline d & $\mathrm{O}$ & 6.07 & 6.64 & 0.348 & -8.28 & -5.72 & -0.063 & 0.220 & -0.448 & 1.680 \\
\hline e & $\mathrm{S}$ & 6.93 & 7.94 & 0.556 & -8.42 & -6.76 & 0.002 & 0.337 & -0.322 & 1.102 \\
\hline $3 \mathrm{a}$ & $\mathrm{H}^{\mathrm{f}}$ & $\begin{array}{c}10.38 \\
(13.69)\end{array}$ & 10.30 & $\begin{array}{c}0.689 \\
(0.849)\end{array}$ & $\begin{array}{c}-12.51 \\
(-13.00)\end{array}$ & $\begin{array}{l}-11.70 \\
(-12.34)\end{array}$ & -0.066 & -0.292 & 0.068 & 0.805 \\
\hline $\mathrm{b}$ & $\mathrm{SCH}_{3}$ & 9.22 & 9.07 & 0.618 & -10.57 & -10.10 & -0.074 & -0.166 & -0.040 & 1.120 \\
\hline
\end{tabular}

${ }^{a}$ Calculated at the B3LYP/6-31+G*//B3LYP/6-31+G* level according to Scheme 2. ${ }^{\mathrm{b}}$ Solvent (ethanol) effects computed using the PCM (COSMO) method. ${ }^{\mathrm{c}}$ Calculated using equation $17 .{ }^{\mathrm{d}}$ Calculated with the GIAO method at the HF/6-311+G**//B3LYP/6-31+G* level. ${ }^{\mathrm{e}} \mathrm{CHELPG}$ charges and WBI computed at the B3LYP/6-311G**//B3LYP/6-31+G* level. ${ }^{\mathrm{f}}$ Data in parentheses taken from ref. 7, with the geometry optimized at the MP2(fc) $/ 6-311+\mathrm{G}^{* *}$ level, ASE corrected for ZPE at the same level, and NICS computed with the GIAO/HF/6-311+G** method.

$$
\begin{aligned}
& \mathrm{HOMA}=1-\mathrm{EN}-\mathrm{GEO} \\
& \mathrm{EN}=\alpha\left(r_{a v}-R_{o p t}\right)\left|r_{a v}-R_{o p t}\right|
\end{aligned}
$$




$$
\mathrm{GEO}=\frac{\alpha}{\mathrm{N}} \sum_{i=1}^{\mathrm{N}}\left(r_{a v}-r_{i}\right)^{2}
$$

HOMA data for the thiadiazole derivatives 1-3 studied herein are listed in Table 2 (see supplementary information for EN and GEO values).

NICS are obtained as the negative value of absolute magnetic shieldings at revealing points in or above the centroid of a ring system. ${ }^{10}$ Negative values of $\mathrm{NICS}(0)$, computed at the ring centroid, or NICS(1), $1 \AA$ above the centroid, correspond to aromatic systems and, as a general trend, the more negative is NICS, the more aromatic are the rings. Conversely, positive NICS values are associated with anti-aromaticity. As far as NICS constitute a measure of the diatropic ring-current due to the aromatic $\pi$-electron system, NICS(1) values are often considered to better reflect this effect of $\pi$-electrons because of the lowering of paratropic contamination of the ring(and exocyclic-) $\sigma$-bonds. Using the standard GIAO method implemented in the Gaussian series of programs, we have computed $\mathrm{NICS}(0)$ and $\mathrm{NICS}(1)$ values for thiadiazole derivatives 1-3 (Table 2) at the same level as other relevant comparative NICS studies, ${ }^{7}$ provided that diatropicity is relatively insensitive to geometric variations in aromatic systems, ${ }^{36}$ but computed absolute NICS values (not comparative trends) are significantly influenced by the calculation level.

As expected, all the thiadiazolium cations (1) display high to moderate aromaticity with ASE values $(8.7-5.6 \mathrm{kcal} / \mathrm{mol})$ just below those of the neutral thiadiazoles (3) taken as the reference, whereas the thiadiazolines (2) are only modestly aromatic, except for 2-oxo- (2d) and 2-thioxo1,3,4-thiadiazoline (2e) which have unexpectedly high ASE values. The HOMA and NICS(1) descriptors also point in the same direction, the 2-dicyanomethylene- (2a) and 2-thioxothiadiazoline (2e) being the most structurally and magnetically aromatic within the group of (formally) semi-unsaturated ring systems. It is worth noting that the HOMA criterion must receive some criticism as it disagrees with the other two well-established criteria in predicting an aromatic character for neutral thiadiazoles, falling within the range of the cationic derivatives. We believe that this could arise from cumulative errors in the virtual $\mathrm{C}-\mathrm{C}$ bond approach, at least for these heterocyclic rings with a high content of heteroatoms.

The scatter plots of several aromaticity descriptors against-NICS(1) (Figure 2) confirm the expected general tendency toward mutual dependence and the significantly good correlations among these parameters. Thus a nice linear correlation is observed for ASE $\left(\mathrm{R}^{2}=0.9775\right)$ when compounds $\mathbf{2 b}$, 2d and 2e (light-gray triangles in Figure 2) are excluded. Also, a satisfactory second-order polynomial correlation $\left(\mathrm{R}^{2}=0.9449\right)$ is displayed by the HOMA plot, turning to a good linear dependence $\left(\mathrm{R}^{2}=0.9644\right)$ if compounds $\mathbf{2 b}-\mathbf{d}$ are omitted (dark gray squares in Fig. 2). 


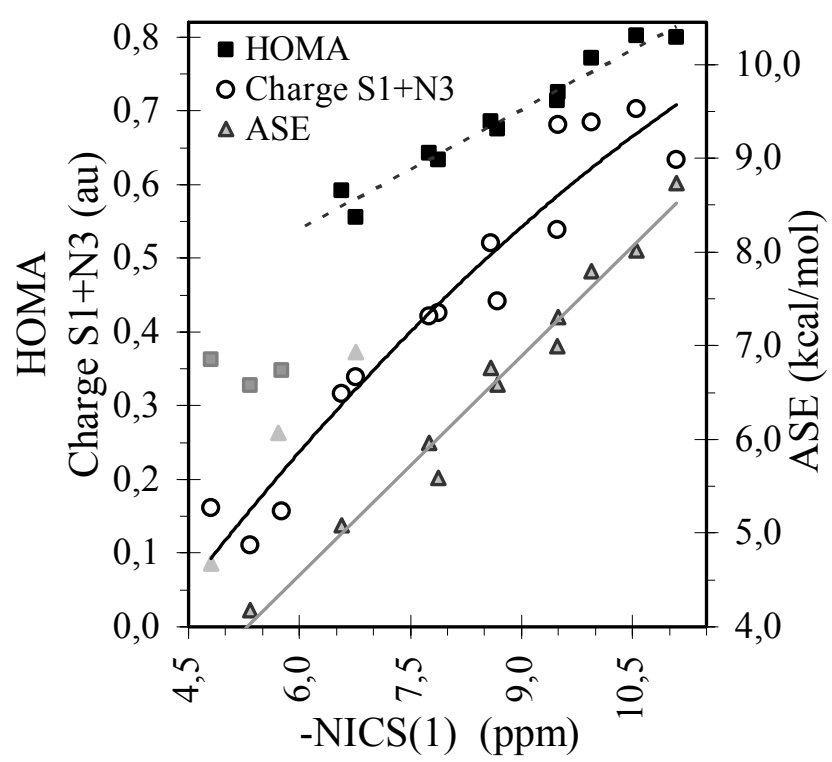

Figure 2. Best correlations in aromaticity descriptors for compounds $\mathbf{1}$ and $\mathbf{2}$.

It is noteworthy that ASE values computed in ethanol (Table 2) remain almost unchanged for neutral thiadiazoles (3) but increase considerably for cationic thiadiazolium derivatives (1) and modestly for the thiadiazolines (2).

The aforementioned decrease of aromaticity of cationic thiadiazolium systems (1) compared with the neutral N-3- unsubstituted analogs (3) can be rationalized in the light of the valence bond (VB) theory by taking into consideration a significant contribution of the resonance structure $\mathbf{1}^{\text {III }}$ (Scheme 3) where Hückel's rule is not fulfilled. Indeed, structures I, II and III are expected to account for a positive charge spreading mainly over N-3, S-1 and the C-2substituent, respectively. Excluding 1a,b, the CHELPG (CHarges from ELectrostatic Potentials using a Grid method) charge distribution calculated for compounds 1 (Table 2) supports this formulation as it points to a higher positive charge density over N-3 (0.26-0.47 au) and S-1 $(0.15-0.28 \mathrm{au})$, mainly due to Hückel type structures $\left(\mathbf{1}^{\mathbf{I}}\right.$ and $\left.\mathbf{1}^{\mathbf{I I}}\right)$, and $c a$ 6-30\% over the C-2 substituent, mainly due to the non-Hückel structure $\mathbf{1}^{\text {III }}$. The last is characterized by an exocyclic double bond at C-2, in good agreement with high Wiberg bond index (WBI) values in the range 1.15-1.32. Compound 1b lacks the possibility of delocalizing the positive charge over the C-2substituent except by the inductive effect or by isovalent hyperconjugation $\left(\mathrm{WBI}_{\mathrm{C}-\mathrm{H}}=0.823\right)$. 2Hydroxy-1,3,4-thiadiazolium cation (1e) has, by far, the lowest positive charge density over the exocyclic substituent and with lowest $\mathrm{WBI}_{\mathrm{C} 2-\mathrm{Z}}$ value. Although the extent of positive charge over the substituent $\mathrm{Z}$ is not necessarily proportional to the contribution of the resonant structure bearing it, one can conclude that structure $\mathbf{1}^{\mathrm{III}}$ is relevant enough to account for a significant decrease in the aromaticity of 2- substituted thiadiazolium cations $\mathbf{1}$, in accordance with that suggested by ASE and NICS data. Interestingly, the degree of methyl- substitution at the Z- $\alpha$ - 
heteroatom (N, O, or S) directly linked to C-2 (on moving from 1c, 1e and $\mathbf{1 g}$ to $\mathbf{1 d}$, $\mathbf{1 f}$ and $\mathbf{1 h}$, respectively) promotes a reduction in ASE ( $c a 0.3 \mathrm{kcal} / \mathrm{mol}$ ) and HOMA (ca 0.01$)$ values and an increase in the $\mathrm{WBI}_{\mathrm{C} 2-\mathrm{Z}}$ ( $\left.c a 0.015\right)$, presumably as a consequence of the stabilization of structures $\mathbf{1}^{\text {III }}$ by the inductive effect.
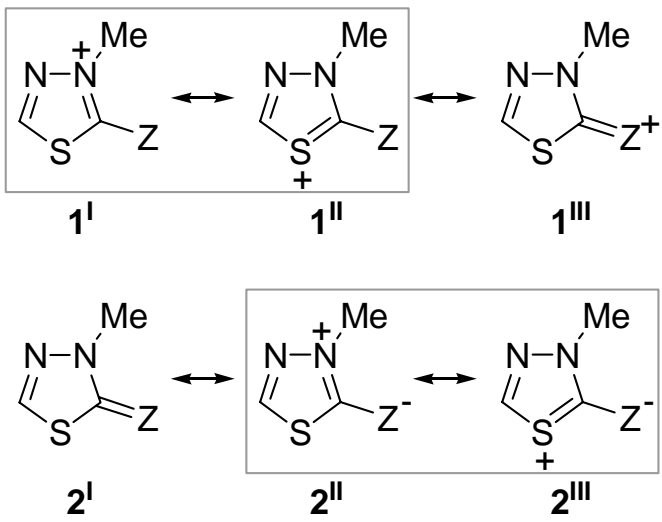

Scheme 3. Expected resonance hybrids and charge distribution pattern for compounds 1 and 2.

Analogously, a VB analysis for thiadiazolines 2 shows three principal contributing resonant structures. High negative values for CHELPG charges over the C-2- substituent, mainly for 2a $\left(\mathrm{Z}: \mathrm{C}(\mathrm{CN})_{2}\right)$ and $\mathbf{2 d}(\mathrm{Z}: \mathrm{O})$ in the expected order of group electronegativities, together with high positive charge density at N-3 (within the range $0.22-0.34 \mathrm{au}$ ) strongly suggest a prevailing contribution of Hückel-type structures $\mathbf{2}^{\mathbf{I I}}$, even over the fully uncharged species $\mathbf{2}^{\mathbf{I}}$, as confirmed by the low to moderate WBI values for the exocyclic, "double bond" at C2 (1.10-1.75). For compound $\mathbf{2 e}$, the latter unexpectedly falls below the corresponding range in the thiadiazolium cations $\mathbf{1}$, which is probably due to HOMO-3 which promotes a relatively strong $\mathrm{S} 1 \cdots \mathrm{S}_{\text {exo }}$ bonding interaction $\left(\mathrm{WBI}_{\mathrm{S} 1-\mathrm{Sexo}}=0.202\right)$, mainly involving in-plane $\mathrm{AO}$ with high $p$-character for both atoms, also accounting for the rather high ASE value for this compound. Overall, these facts point to a significant increase in aromatic character for thiadiazolines 2 , increasing in the sequence $\mathrm{Z}=\mathrm{NH} \approx \mathrm{NMe}<\mathrm{O}<(\mathrm{NC})_{2} \mathrm{C}<<\mathrm{S}$, which agrees with the previously mentioned aromaticity descriptors. On moving from $\mathbf{2 b}$ to $\mathbf{2 c}$, the inductive effect of the methyl substitution at the exocyclic $\mathrm{N}$ - atom destabilizes the negative charge over $\mathrm{Z}$ in the Hückel-type structures $2^{\text {II }}$ and $2^{\mathrm{III}}$, thus explaining the lowering in ASE, HOMA, and the charge separation.

As for other aromaticity indices, a rough second-order polynomial dependence $\left(R^{2}=0.9307\right)$ is observed in the plot of the summed CHELPG charges over S-1 and N-3 against-NICS(1) for all compounds 1 and 2 (Figure 2).

On the other hand, a second type of analysis is concerned with the interaction taking place between the reactants, and is therefore related to kinetic concepts. A simple inspection of the calculated MO for thiadiazolium 1h (Figure 3) reveals the existence of a low-lying (hard) acceptor orbital LUMO of $\pi$-symmetry, with significant coefficients over C-2 (also, LUMO+2 
has analogous features) that should account, on the basis of the HSAB-principle, for the more favorable donor-acceptor interaction with hard nucleophiles. Indeed, the HOMO of simple O- or $\mathrm{N}$ - nucleophiles such as $\mathrm{H}_{2} \mathrm{O}, \mathrm{MeOH}, \mathrm{NH}_{3}$ or $\mathrm{MeNH}_{2}$ lies slightly below the energy of the $\mathbf{1 h}$ LUMO. On the contrary, both LUMO+1 and LUMO+5 have significant coefficients over the Smethyl C- atom with antibonding character for the $\mathrm{S}-\mathrm{C}$ (methyl) bond. Thus, these softer acceptor orbitals are expected to be involved in the S- demethylation processes by the action of softer nucleophiles like S- nucleophiles, and carboxylate or halide salts. Similarly, LUMO+11 of 1h would be involved in $\mathrm{N}$-demethylation reactions leading to $\mathbf{3 b}$, which has never been observed experimentally.

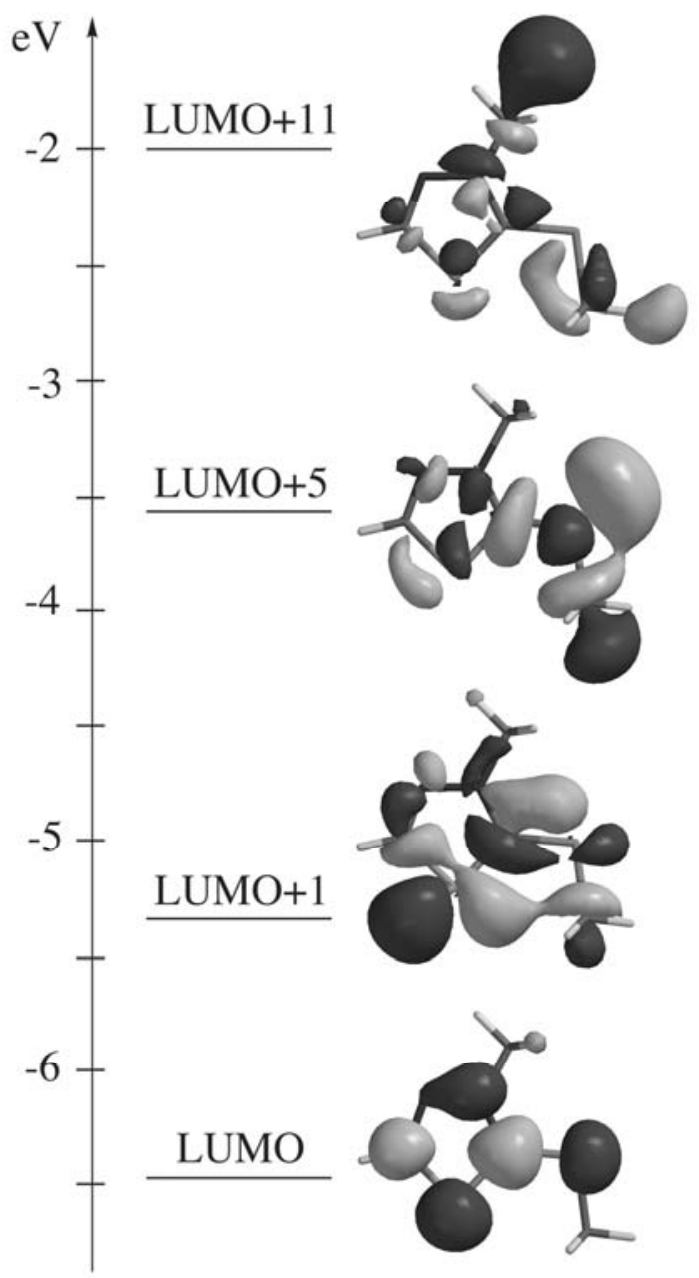

Figure 3. Relevant acceptor orbitals (0.035 isovalue) of $\mathbf{1 h}$ calculated at the B3LYP/6-31+G* level.

It is noteworthy that $\mathrm{LUMO}+4(-3.727 \mathrm{eV})$ exhibits high coefficients similarly distributed at the S- and $\mathrm{N}$ - methyl $\mathrm{C}$ atoms, with rough $s p^{3}$ - antibonding symmetry, as well as two highly 
diffuse lobes at $c a 1.69 \AA$ above and below the molecular plane, that could account for $\pi$ complex formation with the nucleophiles before the attack.

In order to analyze the electrophilic behavior of the title compound $\mathbf{1 h}$ in another way we have also studied the interaction potential of 3-methyl-2-methylthio-1,3,4-thiadiazolium cation vs several negative particles as models for nucleophiles, using the MIPp method. For the calculation of MIPp energy maps for $\mathbf{1 h}, \mathrm{O}^{-}$was used as a model for O-nucleophiles and $\mathrm{S}^{-}$as a model for S- nucleophiles; both $\mathrm{O}^{-}$and $\mathrm{S}^{-}$ions were considered as classical non-polarization particles, as described elsewhere. ${ }^{37}$ We first explored the interaction potential of $\mathbf{1 h}$ interacting with $\mathrm{O}^{-}$, denoted as $\mathrm{MIPp}\left(\mathrm{O}^{-}\right)$, in two bi-dimensional planes (2D). One $2 \mathrm{D}-\mathrm{MIPp}\left(\mathrm{O}^{-}\right)_{0}$ energy map (Figure 4) was computed at the molecular plane and gives information related to the possible $\mathrm{S}$ - and $\mathrm{N}$ - demethylation processes. The second energy map $2 \mathrm{D}-\mathrm{MIPp}\left(\mathrm{O}^{-}\right)_{2.2}$ was computed at $2.2 \AA$ above the molecular plane and parallel to it, giving information related to nucleophilic attack at C-2. The distance of $2.2 \AA$ is chosen because the global MIPp minimum has been found at this distance above the molecular ring. Similarly, for the interaction with $\mathrm{S}^{-}$we have computed two energy maps, one $2 \mathrm{D}-\mathrm{MIPp}\left(\mathrm{S}^{-}\right)_{0}$ at the molecular plane and the other 2D$\operatorname{MIPp}\left(\mathrm{S}^{-}\right)_{3.1}$ computed $3.1 \AA$ above the molecular plane and parallel to it (Figure 4). The isocontour lines are represented at every $25 \mathrm{kcal} / \mathrm{mol}$ from -75 to 25 , the solid and dashed isocontour lines corresponding to positive and negative energy values, respectively, and the gray dashed lines to the lowest isovalue. In the 2D- $\mathrm{MIPp}\left(\mathrm{O}^{-}\right)$maps (Figure 4, up) an additional isocontour line corresponding to an energetic potential of $-100 \mathrm{kcal} / \mathrm{mol}$ is shown, whereas for the 2D-MIPp $\left(\mathrm{S}^{-}\right)_{3.1}$ map (Figure 4, bottom-right) only two isocontour lines are represented, i.e., 50 and $-75 \mathrm{kcal} / \mathrm{mol}$. The different behavior of $\mathrm{O}$ - and $\mathrm{S}$-nucleophiles can be rationalized using the information provided by the MIPp calculations. Comparison of the maps shows the following: first, the topologies of $2 \mathrm{D}-\mathrm{MIPp}\left(\mathrm{O}^{-}\right)$and $2 \mathrm{D}-\mathrm{MIPp}\left(\mathrm{S}^{-}\right)$energy maps computed at the molecular plane are similar, while those computed above the molecular planes are quite different. Secondly, the preference of O-nucleophiles to attack at $\mathrm{C} 2$ can be explained by comparing the two 2D-MIPp $\left(\mathrm{O}^{-}\right)$maps. In the $2 \mathrm{D}-\mathrm{MIPp}\left(\mathrm{O}^{-}\right)_{0}$ map the spatial regions where the interaction of $\mathbf{1 h}$ with $\mathrm{O}^{-}$is more favorable are neither in the proximity of $\mathrm{N}-\mathrm{CH}_{3}$ nor $\mathrm{S}_{-} \mathrm{CH}_{3}$ groups whereas in the $2 \mathrm{D}-\mathrm{MIPp}\left(\mathrm{O}^{-}\right)_{2.2}$ energy map the spatial region where the interaction is more favorable is close to $\mathrm{C}-2$. In fact, the global minimum, represented by a star, is located near the orthogonal projection of the $\mathrm{C}-2$ carbon atom. Also, the density of isocontour lines near the $\mathrm{C}-2$ region is considerable, indicating the existence of a potential well and consequently the attack of O- nucleophiles to $\mathbf{1 h}$ cation is directed through this area to the $\mathrm{C}-2$ carbon atom. Third, and conversely, the $2 \mathrm{D}-\mathrm{MIPp}\left(\mathrm{S}^{-}\right)$energy maps show no clear preference of $\mathrm{S}^{-}$for $\mathrm{C}-2$ or $\mathrm{S}-\mathrm{CH}_{3}$ electrophilic regions. Inspection of the isocontour lines in the $2 \mathrm{D}-\mathrm{MIPp}\left(\mathrm{S}^{-}\right)_{3.1}$ energy map (see Figure 4, bottom-right) demonstrates that there is a wide spatial region where the interaction potential is $-75 \mathrm{kcal} / \mathrm{mol}$ (gray dashed line), indicating that, in contrast to $\mathrm{O}^{-}$, the $\mathrm{S}^{-}$presents an unrestricted movement in a wide area when it interacts with the 1h cation. Additionally, the 2D$\operatorname{MIPp}\left(\mathrm{S}^{-}\right)_{0}$ energy map shows a wide area where the potential is below $-75 \mathrm{kcal} / \mathrm{mol}$ (gray dashed 
lines) and, interestingly, it reaches the proximity of the $\mathrm{S}_{-} \mathrm{CH}_{3}$ group despite the greater size of the interacting S- particle.

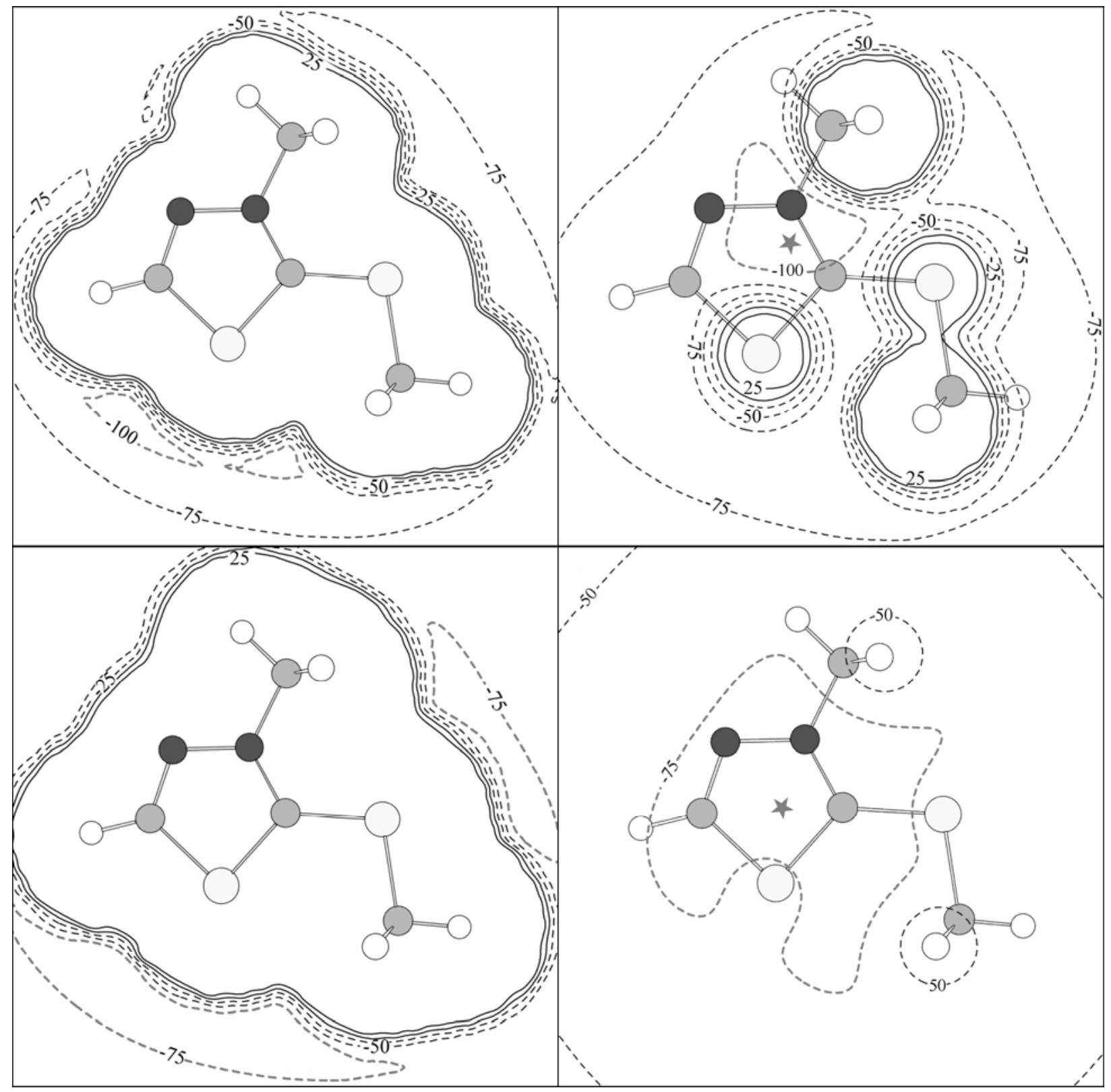

Figure 4. 2D-MIPp energy maps (isovalues in $\mathrm{kcal} / \mathrm{mol}$ ) of $\mathbf{1 h}$ versus $\mathrm{O}^{-}$(up) and $\mathrm{S}^{-}$(down) at either the molecular plane (left) and $2.2 \AA\left(\mathrm{O}^{-}\right)$or $3.1 \AA\left(\mathrm{S}^{-}\right)$above it (right).

The MIPp method also provides a natural partitioning of the interaction energy into intuitive components, i.e., electrostatic $\left(E_{\mathrm{e}}\right)$, polarization $\left(E_{\mathrm{p}}\right)$, and van der Waals $\left(E_{\mathrm{vw}}\right)$. The approach of the nucleophile to $\mathrm{C}-2$ has been performed by supposing a perpendicular trajectory, whereas the trajectories to $\mathrm{S}-\mathrm{CH}_{3}$ and $\mathrm{N}-\mathrm{CH}_{3}$ have been computed in the $\mathrm{S}-\mathrm{C}$ and the $\mathrm{N}-\mathrm{C}$ bond directions, 
respectively. We have computed the values of MIPp starting at $4 \AA$ from the electrophile center and getting closer in steps of $0.1 \AA$. For the interaction of $\mathbf{1 h}$ with $\mathrm{O}^{-}$, the computed terms at the global minimum ( $2.2 \AA$ from the C-2) are $E_{\mathrm{e}}=-102.2, E_{\mathrm{p}}=-25.6$ and $E_{\mathrm{vw}}=8.9 \mathrm{kcal} / \mathrm{mol}$, and the total contribution is $E_{\mathrm{t}}=-118.8 \mathrm{kcal} / \mathrm{mol}$. The corresponding values computed for the interaction of $1 \mathbf{h}$ with $\mathrm{S}^{-}$at the global minimum (3.1 $\AA$ from the C-2) are $E_{\mathrm{e}}=-82.1, E_{\mathrm{p}}=-8.9$ and $E_{\mathrm{vw}}=4.0$ $\mathrm{kcal} / \mathrm{mol}$, the total contribution being $E_{\mathrm{t}}=-87.1 \mathrm{kcal} / \mathrm{mol}$. The $\mathrm{O}^{-}$anion is more polarizing than $\mathrm{S}^{-}$because of its smaller van der Waals radius, which allows it to get closer to the $\pi$ system of 1h. This is clearly reflected in the MIPp contributions at the minimum, the polarization term $\left(E_{\mathrm{p}}\right)$ being almost three times higher in the interaction of $\mathbf{1 h}$ with $\mathrm{O}^{-}$than with $\mathrm{S}^{-}$. This is a likely explanation for the preference of O-nucleophiles for the C-2 attack, which implies a $\pi$ approximation to the $\mathbf{1 h}$ ring and the consequent stabilization due to polarization effects. This extra stabilization is diminished in the approximation of $\mathrm{S}^{-}$, in agreement with experimental results showing that S- nucleophiles do not have a preference for C-2. Similar conclusions can be obtained from the MIPp energetic features in the approximation of $\mathrm{C}^{-}, \mathrm{N}^{-}$and $\mathrm{Cl}^{-}$anions to the electrophilic centers of $\mathbf{1 h}$ (see Supplementary Information).

In the context of the reactivity-selectivity descriptors emerging from the HSAB principle, the nucleophiles chosen for studying the reaction with 3-methyl-2-methylthio-1,3,4-thiadiazolium cation (1h) were: (i) simple N-, O-, S- and halide- nucleophiles, such as $\mathrm{NH}_{3}, \mathrm{MeNH}_{2}, \mathrm{H}_{2} \mathrm{O}$, $\mathrm{MeOH}, \mathrm{SH}^{-}, \mathrm{MeS}^{-}, \mathrm{Cl}^{-}$and $\mathrm{Br}^{-}$, (ii) $\mathrm{HCOO}^{-}$in order to study its different behavior relative to other $\mathrm{O}$ - nucleophiles and, (iii) the conjugate base of malononitrile, $(\mathrm{NC})_{2} \mathrm{CH}^{-}$, as a representative $\mathrm{C}$ - nucleophile. In order to fulfill the demand for constant external potential, $\mathrm{v}(\mathbf{r})$, the geometries of all these species were used to calculate the electronic structure (energies and atomic charges) of the related $\mathrm{N} \pm 1$ - electron species required to obtain the vertical ionization potential $I$ and electron affinity $A$, which were used to calculate the chemical potential $\mu$, the global softness $S$, and the global philicity $\omega$ from eqs. 3, 4 and 12. The atomic charges required for evaluation of the Fukui function were obtained through eqs. 5-6 using the Mulliken population analysis (MPA), because natural or CHELPG charges gave systematically worse results. In addition, the condensed local softness and philicity, and the group philicity were calculated according to eqs. 7, 13 and 15, respectively. All relevant reactivity-selectivity indices are collected in Table 3 (see Supplementary Information for total electronic energies, HOMO and LUMO eigenvalues, vertical ionization potentials, and electron affinities).

The criterion of minimum quadratic difference in softness $\Delta_{j}^{s}$, where $j$ represents all of the reactive sites in $\mathbf{1 h}$, was evaluated according to eq. 8 , as suggested by Geerlings and his coworkers ${ }^{26}$ but we did not obtain satisfactory results - they systematically failed when we used local-global or local-local viewpoints, or even when we corrected the condensed local softnesses by the group softnesses (see Supplementary Information). Nevertheless, group philicity values derived from the MPA scheme have provided the expected reactivity trends for nucleophilic attack towards the three electrophilic sites in $\mathbf{1 h}$ (Table 3). 
Table 3. Selected global, local condensed, and group reactivity indices for $\mathbf{1 h}$ and nucleophiles (in atomic units)

\begin{tabular}{|c|c|c|c|c|c|c|c|}
\hline & $\mu^{\mathrm{a}}$ & $S^{\mathrm{a}}$ & $\omega^{\mathrm{a}}$ & $f^{ \pm \mathrm{b}}$ & $s^{ \pm \mathrm{b}}$ & $\omega^{ \pm b}$ & $\omega_{\mathrm{g}}^{ \pm \mathrm{b}}$ \\
\hline & & & & $f^{+}$ & $s^{+}$ & $\omega^{+}$ & $\omega_{\mathrm{g}}^{+}$ \\
\hline 1h $\underline{\mathrm{C}}-2$ & & & & -0.1042 & -0.311 & -0.035 & -0.060 \\
\hline 1h $\mathrm{SCH}_{3}$ & -0.3367 & 2.9853 & 0.3385 & 0.0203 & 0.061 & 0.007 & 0.001 \\
\hline \multirow[t]{2}{*}{$1 \mathbf{h} \mathrm{NCH}_{3}$} & & & & 0.0127 & 0.038 & 0.004 & 0.005 \\
\hline & & & & $f^{-}$ & $s^{-}$ & $\omega^{-}$ & $\omega_{\mathrm{g}}^{-}$ \\
\hline$(\mathrm{NC})_{2} \underline{\mathrm{CH}}_{2}$ & -0.2161 & 2.1270 & 0.0993 & -0.0196 & -0.042 & -0.002 & -0.063 \\
\hline$\underline{\mathrm{NH}}_{3}$ & -0.1567 & 2.0724 & 0.0509 & -0.5636 & -1.168 & -0.029 & -0.051 \\
\hline $\mathrm{MeNH}_{2}$ & -0.1500 & 2.4764 & 0.0557 & -0.3892 & -0.964 & -0.022 & -0.034 \\
\hline $\mathrm{H}_{2} \underline{\mathrm{O}}$ & -0.1794 & 1.7401 & 0.0560 & -0.7009 & -1.220 & -0.039 & -0.056 \\
\hline $\mathrm{Me} \underline{\mathrm{OH}}$ & -0.1732 & 2.2017 & 0.0661 & -0.7657 & -1.686 & -0.051 & -0.035 \\
\hline $\mathrm{HCO}^{-}$ & 0.0428 & 2.7562 & 0.0050 & -0.2936 & -0.809 & -0.001 & -0.002 \\
\hline$\underline{\mathrm{S}} \mathrm{H}^{-}$ & 0.0727 & 3.1588 & 0.0167 & -0.8910 & -2.815 & -0.015 & -0.017 \\
\hline $\mathrm{MeS}^{-}$ & 0.0589 & 3.9177 & 0.0136 & -0.8005 & -3.136 & -0.011 & -0.010 \\
\hline $\mathrm{Cl}^{-}$ & 0.0674 & 2.4531 & 0.0111 & -1.0000 & -2.453 & -0.011 & -0.011 \\
\hline $\mathrm{Br}^{-}$ & 0.0462 & 2.8142 & 0.0060 & -1.0000 & -2.814 & -0.006 & -0.006 \\
\hline
\end{tabular}

${ }^{\mathrm{a}}$ Calculated at B3LYP/6-31+G* from electronic energies uncorrected for the ZPE. ${ }^{\mathrm{b}}$ Calculated from Mulliken charges at B3LYP/6-311G**//6-31+G*.

Moreover, an analogous criterion of, minimum quadratic difference in philicity, $\Delta_{j}^{\omega}$, can be defined (Eq. 20) - either at the condensed or group level - by the statement that the reaction site $\mathrm{b}_{l}$ of a molecule $\mathrm{B}$, with a philicity $\omega_{\mathrm{B} l}$, will interact preferentially with another molecule, $\mathrm{A}$, containing several possible interaction sites $\mathrm{a}_{j}(\mathrm{j}=1,2, \ldots)$ to yield the smallest of the possible $\Delta_{j}^{\omega}$ values, i.e., at the site in A with the closest possible value of the corresponding (opposite) type of philicity.

$$
\Delta_{j}^{\omega}=\left(\omega_{\mathrm{Aj}}-\omega_{\mathrm{B} l}\right)^{2}
$$

In Table 4 the quadratic differences between $\omega_{\mathrm{g}}^{-}$for the nucleophiles (group nucleophilicity) and every $\omega_{\mathrm{g}}^{+}$(group electrophilicity) for all three electrophilic sites in $\mathbf{1 h}$ are collected.

This analysis agrees with the experimental results: all $\mathrm{N}$ - and simple $\mathrm{O}$ - nucleophiles, as well as the only tested $\mathrm{C}$ - nucleophile, having $\omega_{\mathrm{g}}^{-} \leq-0.03 \mathrm{au}$, behave as hard nucleophiles - using the conventional HSAB terminology - thus preferring attack at the hard electrophilic site, C-2 $\left(\omega_{\mathrm{g}}^{+}=-0.06 \mathrm{au}\right)$, and yielding the smallest $\Delta_{j}^{\omega}$ value for this path, whereas S- and halidenucleophiles, as well as carboxylate ions, have nearly vanishing $\omega_{\mathrm{g}}^{-}$values (ranging from -0.02 
to almost $0.00 \mathrm{au})$, thus preferring the attack at the softer S-methyl $\mathrm{C}$ - atom $\left(\omega_{\mathrm{g}}^{+}=0.00 \mathrm{au}\right)$, the $\Delta_{j}^{\omega}$ value for this path being the smallest. It is worth noting that in no case would the attack be favored at the N-methyl C-atom, which would require the use of even softer nucleophiles.

Table 4. Quadratic group philicity differences (in a.u.) and interaction energies (in $\mathrm{kcal} / \mathrm{mol}$ ) for all studied nucleophiles towards the electrophilic sites in $\mathbf{1 h}$

\begin{tabular}{lccccccccc}
\hline & \multicolumn{3}{c}{$\Delta_{j}^{\omega}\left(\cdot 10^{3}\right)$} & \multicolumn{3}{c}{$\Delta \mathrm{E}_{\text {int }}$} & \multicolumn{3}{c}{$\Delta \Delta \mathrm{E}_{\text {int }}(\lambda=0.08)$} \\
\hline & $\mathrm{C}-2$ & $\mathrm{SMe}$ & $\mathrm{NMe}$ & $\mathrm{C}-2$ & $\mathrm{SMe}$ & $\mathrm{NMe}$ & $\mathrm{C}-2$ & $\mathrm{SMe}$ & $\mathrm{NMe}$ \\
\hline$(\mathrm{NC})_{2} \underline{\mathrm{CH}}_{2}{ }^{\mathrm{a}}$ & 0.01 & 4.04 & 4.58 & $232.1 \lambda+10.29$ & $320.1 \lambda-2.76$ & $312.9 \lambda-1.69$ & 6.01 & 0.00 & 0.49 \\
$\underline{\mathrm{NH}}_{3}$ & 0.09 & 2.68 & 3.12 & $212.1 \lambda+2.50$ & $283.3 \lambda-0.65$ & $277.6 \lambda-0.40$ & 0.00 & 2.55 & 2.34 \\
$\mathrm{MeNH}_{2}$ & 0.70 & 1.20 & 1.50 & $246.1 \lambda+2.57$ & $347.3 \lambda-0.65$ & $338.8 \lambda-0.43$ & 0.00 & 4.82 & 4.41 \\
$\mathrm{H}_{2} \underline{\mathrm{O}}$ & 0.02 & 3.23 & 3.71 & $205.0 \lambda+1.93$ & $270.7 \lambda-0.50$ & $265.5 \lambda-0.30$ & 0.00 & 2.84 & 2.61 \\
$\mathrm{Me} \underline{\mathrm{OH}}$ & 0.66 & 1.25 & 1.56 & $157.1 \lambda+2.20$ & $193.0 \lambda-0.53$ & $190.4 \lambda-0.32$ & 0.00 & 0.14 & 0.13 \\
$\mathrm{HCO}^{-}$ & 3.40 & 0.01 & 0.05 & $280.0 \lambda+10.16$ & $419.1 \lambda-2.96$ & $406.7 \lambda-1.80$ & 1.99 & 0.00 & 0.18 \\
$\underline{\mathrm{SH}}^{-}$ & 1.89 & 0.31 & 0.47 & $100.4 \lambda+14.74$ & $113.9 \lambda-3.26$ & $113.0 \lambda-2.02$ & 16.91 & 0.00 & 1.16 \\
$\mathrm{Me}^{-}$ & 2.52 & 0.12 & 0.22 & $91.0 \lambda+13.90$ & $102.0 \lambda-3.03$ & $101.3 \lambda-1.88$ & 16.06 & 0.00 & 1.08 \\
$\mathrm{Cl}^{-}$ & 2.41 & 0.14 & 0.26 & $113.5 \lambda+14.15$ & $131.1 \lambda-3.18$ & $129.9 \lambda-1.97$ & 15.92 & 0.00 & 1.11 \\
$\mathrm{Br}^{-}$ & 2.94 & 0.05 & 0.12 & $100.4 \lambda+12.89$ & $113.9 \lambda-2.85$ & $113.0 \lambda-1.77$ & 14.65 & 0.00 & 1.01 \\
\hline
\end{tabular}

${ }^{\mathrm{a}} \Delta \mathrm{E}_{\mathrm{int}}$ and $\Delta \Delta \mathrm{E}_{\mathrm{int}}$ referred to the conjugate base $(\mathrm{NC})_{2} \mathrm{CH}^{-}$.

In order to discover more about the energetic extent of the above-mentioned preferences, the interaction energies have been calculated by means of eqs. 10 and 11 at the local-local level, therefore using the local softness for both reagents. The resulting expressions are summarized in Table 4 as a function of $\lambda$. In all cases, the charge-transfer $\Delta \mathrm{E}_{\mathrm{v}}$ terminus is more advantageous for attack at the S-methyl C- atom than at C-2 by $2.4-18.0 \mathrm{kcal} / \mathrm{mol}$, especially for soft nucleophiles. In contrast, the charge-reshuffling $\Delta \mathrm{E}{ }_{\mu}{ }_{\mu}$ terminus is always a positive contribution systematically favoring the attack at $\mathrm{C}$-2, especially for hard nucleophiles. Lacking another way to obtain meaningful values of $\lambda$, which in turn could vary from one nucleophile to another, and also for all three different types of nucleophilic attacks, an estimated value of $\lambda=0.08$ would give the overall interaction energy in agreement with experiments. Because of our interest in the comparative purpose of the obtained interaction energies, a value for $\Delta \Delta \mathrm{E}_{\text {int }}$ has been calculated relative to the lower (more favorable) one for every nucleophile (Table 4).

The only value which disagrees with the experimental results is the calculated interaction energy for malononitrile carbanion that should (but actually does not) reflect its experimentally observed preference for attack at C-2. ${ }^{38}$

Similar tendencies were observed in the interaction energies when these were computed and the zero-point vibrational energy correction and the solvent effects were taken into account (see 
the Supplementary Information). However, in this case, the quadratic differences in softness or philicity did not reproduce the observed experimental trends.

In summary, thermodynamic and kinetic criteria together explain the experimentally observed preference of hard nucleophiles to promote nucleophilic displacement of methanethiol at $\mathrm{C}$-2 in their reactions with methylthio-1,3,4-thiadiazolium salts $\mathbf{1 h}$, whereas soft nucleophiles achieve the S-demethylation of $\mathbf{1 h}$ leading to $\mathbf{2 e}$. The characterization of the minimum energy paths for these reactions currently under investigation, because it should provide a complete understanding of the preferred paths in every case, and show whether this preference is concerned with kinetic or thermodynamic control. In addition, several criteria used in the assessment of aromaticity evaluation reveal an unexpectedly high aromatic character, and thus high stabilization, for both thiadiazolium cations $\mathbf{1}$ and even for the neutral thiadiazoline derivatives 2 .

\section{Experimental Section}

General Procedures. Calculations were performed with the Gaussian 03 set of programs. ${ }^{39}$ All structures were fully optimized by using the B3LYP functional ${ }^{40}$ (Becke's three parameters hybrid functional ${ }^{41}$ with the Lee-Yang-Parr correlation functional ${ }^{42}$ ) and the $6-31+\mathrm{G}^{*}$ basis set. Harmonic frequency calculations ${ }^{43}$ verified the nature of the stationary points as minima (all real frequencies). Solvent effects were computed by SPE calculations at the same level on the in vacuo optimized geometries, using Tomasi's $\mathrm{PCM}^{44}$ and Klamt's form of the conductor reaction field (COSMO). ${ }^{45}$ Bond orders are characterized by Wiberg bond indices ${ }^{46}$ and calculated by the Natural Bond Orbital (NBO) method as the sum of squares of the off-diagonal density matrix elements between atoms, as formulated in terms of the natural atomic orbital (NAO) basis set. Atomic charges were obtained from SPE calculations at the B3LYP/6-311G** level using either the Mulliken ${ }^{47}$ population analysis, the NBO method, or the potential-driven CHELPG ${ }^{48}$ scheme. $^{2}$ Values from the magnetic shielding tensor were obtained using the non-relativistic gaugeincluding atomic orbital (GIAO) ${ }^{49}$ approach as SPE calculations at the HF/6-311+G** level. MIPp energetic features and energy maps were computed using the B3LYP/6-31+G* geometries and the HF/6-31+G* wavefunction by using the MOPETE-98 program. ${ }^{50}$

\section{Supplementary Information}

The following additional details are enclosed: EN and GEO contributions to HOMA for all thiadiazole derivatives 1-3, the MIPp energetic features for the three types of approximations of $\mathrm{C}^{-}, \mathrm{N}^{-}$and $\mathrm{Cl}^{-}$anions to $\mathbf{1 h}$, a Table with total electronic energies for all studied nucleophiles, as well as those for the oxidized and reduced species, their HOMO and LUMO eigenvalues, vertical ionization potentials, electron affinities and quadratic differences in softness with the electrophilic sites in $\mathbf{1 h}$. 


\section{Acknowledgments}

We gratefully acknowledge the DGI-Spain BQU 2001-0014 and Fundación Séneca (CARMSpain) PB/72/FS/02 for funding. A.F. thanks DGICYT-Spain (BDQU-2002-04651) for financial support.

\section{References and Footnotes}

1. (a) Eastman Kodak Co. U.S. Pat. 1970, 3493 556; Chem. Abstr. 1970, 73, 36555. (b) Lubrizol Corp. U.S. Patent, 1981, 4246 126; Chem. Abstr. 1981, 94, 142505.

2. Remers, W. A.; Gibs, G. J.; Wiess, M. J. J. Heterocycl. Chem. 1969, 6, 835. (b) Kurzer, F. Org. Comp. Sulphur, Selenium, Tellurium 1973, 2, 725. (c) Schaefer, G.; Trebst, A.; Buechel, K. H. Z. Naturforsch. (C) 1975, 30, 183. (d) Kurzer, F. Org. Comp. Sulphur, Selenium, Tellurium 1977, 4, 431. Inst. Phys. Chem. Res. Jpn. Kokai 1977, 7725028; Chem. Abstr. 1977, 87, 147054. (e) Reckitt and Colman Products Ltd. Ger. Patent 1978, 2727146; Chem. Abstr. 1978, 88, 105357. (f) Davis, M. Org. Comp. Sulphur, Selenium, Tellurium 1979, 5, 440. (g) Lu, K.; Loo, T. Cancer Chemother. Pharmacol. 1980, 4, 275. (h) Labanauskas, L.; Kalcas, V.; Udrenaite, E.; Gaidelis, P.; Brukstus, A.; Dauksas, V. Pharmazie 2001, 56, 617. (i) Clerici, F.; Pocar, D. J. Med. Chem. 2001, 44, 931. (j) Foroumadi, A.; Soltani, F.; Moshafi, M. H.; Ashraf-Askari, R. Farmaco 2003, 58, 1023. (k) Terzioglu, N.; Gursöy, A. Eur. J. Med. Chem. 2003, 38, 781.

3. Yang, C.; Chen, X.-M.; Lu, X.-Q.; Zhou, Q.-H.; Yang, Y.-S. Chem. Commun. 1997, 2041.

4. Tao, E. U. P.; Christie Jr., C. F. Org. Prep. Proced. Int. 1975, 7, 179. (b) Corburn, R. A.; Bhooshan, B.; Glennon, R. A. J. Org. Chem. 1973, 38, 3974.

5. Fujii, K.; Yoshikawa, H.; Yuasa, M. J. Pharm. Soc. Jpn. 1954, 74, 1056. (b) Kanoaka, M. J. Pharm. Soc. Jpn. 1955, 75, 1149.

6. Molina, P.; Tárraga, A.; Espinosa, A. Heterocycles 1989, 29, 2301. (b) Molina, P.; Tárraga, A.; Espinosa, A. Synthesis 1989, 923. (c) Molina, P.; Espinosa, A.; Tárraga, A.; Hernández Cano, F.; Foces-Foces, M. C. J. Chem. Soc. Perkin Trans. 1 1991, 1159. (d) Molina, P.; Tárraga, A.; Díaz, I.; Espinosa, A.; Gaspar, C. Heterocycles 1993, 36, 1263. (e) Molina, P.; Tárraga, A.; Gaspar, C.; Espinosa, A. J. Org. Chem. 1994, 59, 3665.

7. Cyrañski, M. K.; Krygowski, T. M.; Katritzky, A. R.; Schleyer, P. v. R. J. Org. Chem. 2002, $67,1333$.

8. Hehre, W. J.; McIver, R. T.; Pople, J. A.; Schleyer, P. v. R. J. Am. Chem. Soc. 1974, 96, 7162. (b) Radom, L. J. Chem. Soc., Chem. Commun. 1974, 403. (c) George, P.; Tratchman, M.; Brett, A. M.; Bock, C. W. J. Chem. Soc., Perkin Trans. 2 1977, 1036.

9. Krygowski, T. M. J. Chem. Inf. Comput. Sci. 1993, 33, 70. (b) Krygowski, T. M.; Cyrañski, M. Tetrahedron 1996, 52, 1713. (c) Krygowski, T. M.; Cyrañski, M. Tetrahedron 1996, 52, 
10255. (d) Krygowski, T. M.; Cyrañski, M. Chem. Rev. 2001, 101, 1385. (e) Krygowski, T. M.; Cyrañski, M. Phys. Chem. Chem. Phys. 2004, 6, 249.

10. Schleyer, P. v. R.; Maerker, C.; Dransfield, A.; Jiao, H.; van Eikema Hommes, N. J. R. J. Am. Chem. Soc. 1996, 118, 6317. (b) Cyrañski, M. K.; Krygowski, T. M.; Wisiorowski, M.; van Eikema Hommes, N. J. R.; Schleyer, P. v. R. Angew. Chem., Int. Ed. 1998, 37, 177.

11. Luque, F. J.; Orozco, M. J. Comput. Chem. 1998, 19, 866.

12. Cubero, E.; Luque, F. J.; Orozco, M. Proc. Nat. Acad. Sci. USA 1998, 95, 5976.

13. Scrocco, E.; Tomasi, J. Top. Curr. Chem. 1973, 42, 95.

14. Orozco, M.; Luque, F. J. In Molecular Electrostatic Potential: Concepts and Applications, Murray, J. S.; Send, K., Eds; Elsevier: Amsterdam, 1996; Vol. 3, p 181.

15. Francl, M. M. J. Phys. Chem. 1985, 89, 428.

16. Pearson, R. G. J. Am. Chem. Soc. 1963, 85, 3533. (b) Ho, T. L. Chem. Rev. 1975, 75, 1.

17. Yang, W.; Parr, R. G. Proc. Natl. Acad. Sci. U.S.A. 1985, 82, 6723.

18. Parr, R. G.; Yang, W. In Density-functional theory of atoms and molecules; Oxford University Press: New York, 1989.

19. Parr, R. G.; Pearson, R. G. J. Am. Chem. Soc. 1983, 105, 7512. (b) Gázquez, J. L. In Chemical Hardness; Sen, K. D., Ed.; Struct. Bonding, 1993, 80, 27.

20. Baekelandt, B. G.; Mortier, W. J.; Schoonheydt, R. A. In Chemical Hardness; Sen, K. D., Ed., Struct. Bonding 1993, 80, 187. (b) Pearson, R. G. in Chemical Hardness - Applications from Molecules to Solids; VCH-Wiley: Weinheim, 1997. (c) Geerlings, P.; De Proft, F. Int. J. Mol. Sci. 2002, 3, 276.

21. Geerlings, P.; De Proft, F.; Langenaeker, W. Chem. Rev. 2003, 103, 1793.

22. Parr, R. G.; Donnelly, R. A.; Levy, M.; Palke, W. E. J. Chem. Phys. 1978, 68, 3801.

23. The Fukui function, $f(\mathbf{r})$, was defined as the first-order derivative of the electronic density, $\rho(\mathbf{r})$, with respect to the number of electrons at constant external potential, $f(\mathbf{r})=\left(\frac{\partial \rho(\mathbf{r})}{\partial \mathrm{N}}\right)_{\mathrm{v}}=\left(\frac{\partial \mu}{\partial \mathrm{v}(\mathbf{r})}\right)_{\mathrm{N}}$ Parr, R. G.; Yang, W. J. Am. Chem. Soc. 1984, 106, 4049.

24. Yang, W.; Mortier, W. J. J. Am. Chem. Soc. 1986, 108, 5708.

25. The local softness, $s(\mathbf{r})$, is the change of the electron density with respect to the electronic chemical potential (ref. 17): $s(\mathbf{r})=\left(\frac{\partial \rho(\mathbf{r})}{\partial \mu}\right)_{\mathrm{v}}=S \cdot f(\mathbf{r})$.

26. Damoun, S.; Van deWoude, G.; Méndez, F.; Geerlings, P. J. Chem. Phys. 1997, 101, 886. (b) Ponti, A. J. Phys. Chem. A 2000, 104, 8843.

27. Chattaraj, P. K.; Lee, H.; Parr, R. G. J. Am. Chem. Soc. 1991, 113, 1855. (b) Parr, R. G.; Gázquez, J. L. J. Phys. Chem. 1993, 97, 3939.

28. Parr, R. G.; Chattaraj, P. K. J. Am. Chem. Soc. 1991, 113, 1854.

29. Parr, R. G.; Szentpaly, L. V.; Liu, S. J. Am. Chem. Soc. 1999, 121, 1922. 
30. Chattaraj, P. K.; Maiti, B.; Sarkar, U. J. Phys. Chem. A 2003, 107, 4973. (b) Padmanabhan, J.; Parthasarathi, R.; Sarkar, U.; Subramanian, V.; Chattaraj, P. K. Chem. Phys. Lett. 2004, $383,122$.

31. De Prof, F.; Langenaeker, W.; Geerlings, P. J. Phys. Chem. 1993, 97, 1826. (b) De Prof, F.; Chocho, K; Amira, S.; Geerlings, P. J. Phys. Chem. 1994, 98, 5227. (c) Kishnamurti, S.; Pal, S. J. Phys. Chem. A 2000, 104, 7639.

32. Parthasarathi, R.; Padmanabhan, J.; Elango, M.; Subramanian, V.; Chattaraj, P. K. Chem. Phys. Lett. 2004, 394, 225.

33. Cyrañski, M. K.; Krygowski, T. M.; Schleyer, P. v. R.; Katritzky, A. R. Chem. Listy 2000, 94, 788.

34. Pauling, L. J. Am. Chem. Soc. 1947, 69, 542.

35. See for example: (a) Smith, M. B.; March, J. March's Advanced Organic Chemistry: Reactions, Mechanisms, and Structure, $5^{\text {th }}$ Edn; Wiley, 2001. (b) Carey, F. A.; Sundberg, R. J. Advanced Organic Chemistry, $4^{\text {th }}$ Edn; Springer, 2001.

36. Fleischer, U.; Kutzelnigg, W.; Lazzeretti, P.; Mühlenkamp, V. J. Am. Chem. Soc. 1994, 116, 5298.

37. Aqvist, J. J. Phys. Chem. 1990, 94, 8021.

38. This discrepancy could arise either from the level of approximation in obtaining the working expression for $\Delta \mathrm{E}_{\text {int }}$ (Eq. 10), or from the fact that this carbanion is not actually the interacting nucleophile but an incipient negative charged species formed from malononitrile itself and a base. Indeed, the calculated $\Delta_{j}^{\omega}$ values for malononitrile carbanion $(3.336,0.011$ and 0.054 for attack on $\mathrm{C}-2$, SMe and NMe, respectively) also reflect this wrong tendency, whereas the interaction energies for the acid-base malononitrile-trimethylamine adduct follow the correct order $\left(\Delta \mathrm{E}_{\text {int }} 0.00,1647.75\right.$ and $605.90 \mathrm{kcal} / \mathrm{mol}$ for the $\mathrm{C}-2, \mathrm{SMe}$ and NMe paths, respectively) though with meaningless magnitudes.

39. Gaussian 03, Revision B.03, Frisch, M. J.; Trucks, G. W.; Schlegel, H. B.; Scuseria, G. E.; Robb, M. A.; Cheeseman, J. R.; Montgomery Jr., J. A.; Vreven, T.; Kudin, K. N.; Burant, J. C.; Millam, J. M.; Iyengar, S. S.; Tomasi, J.; Barone, V.; Mennucci, B.; Cossi, M.; Scalmani, G.; Rega, N.; Peterson, G. A.; Nakatsuji, H.; Hada, M.; Ehara, M.; Toyota, K.; Fukuda, R.; Hasegawa, J.; Ishida, M.; Nakajima, T.; Honda, Y.; Kitao, O.; Nakai, H.; Klene, M.; Li, X.; Knox, J. E.; Hratchian, H. P.; Cross, J. B.; Adamo, C.; Jaramillo, J.; Gomperts, R.; Stratmann, R. E.; Yazyev, O.; Austin, A. J.; Cammi, R.; Pomelli, C.; Ochterski, J. W.; Ayala, P. Y.; Morokuma, K.; Voth, G.A.; Salvador, P.; Dannenberg, J. J.; Zakrzewski, V. G.; Dapprich, S.; Daniels, A. D.; Strain, M. C.; Farkas, O.; Malick, D. K.; Rabuck, A. D.; Raghavachari, K.; Foresman J. B.; Ortiz, J. V.; Cui, Q.; Baboul, A. G.; Clifford, S.; Cioslowski, J.; Stefanov, B. B.; Liu, G.; Liashenko, A.; Piskorz, P.; Komaromi, I.; Martin, R. L.; Fox, D. J.; Keith, T.; Al-Laham, M. A.; Peng, C. Y.; Nanayakkara, A.; Challacombe, M.; Gill, P. M. W.; Johnson, B.; Chen, W.; Wong, M. W.; Gonzalez, C.; Pople, J.A. Gaussian, Inc., Pittsburgh PA, 2003. 
40. Bartolotti, L. J.; Fluchick, K. In Reviews in Computational Chemistry, Lipkowitz, K. B.; Boyd, B. D., Eds; VCH: New York, 1996; Vol. 7, pp 187-216.

41. Becke, A. D. J. Chem. Phys. 1993, 98, 5648.

42. Lee, C.; Yang, W.; Parr, R. G. Physical Review B 1988, 37, 785.

43. McIver, J. W.; Komornicki, A. K. J. Am. Chem. Soc. 1972, 94, 2625.

44. Miertus, S.; Scrocco, E.; Tomasi, J. Chem. Phys. 1981, 55, 117. (b) Cammi, R.; Mennucci, B.; Tomasi, J. J. Phys. Chem. A 2000, 104, 5631. (c) Cossi, M.; Rega, N.; Scalmani, G.; Barone, V. J. Comp. Chem. 2003, 24, 669.

45. Eckert, F.; Klamt, A. AIChE J. 2002, 48, 369.

46. Wiberg, K. Tetrahedron 1968, 24, 1083.

47. Mulliken, R. S. J. Chem. Phys. 1955, 23, 1833.

48. Breneman, C. M.; Wiberg, K. B. J. Comp. Chem. 1990, 11, 361.

49. Cheeseman, J. R.; Trucks, G. W.; Keith, T. A.; Frisch, M. J. J. Chem. Phys. 1996, 104, 5497.

50. MOPETE-98 computer program, Luque, F. J.; Orozco, M., Universitat de Barcelona, 1998. 